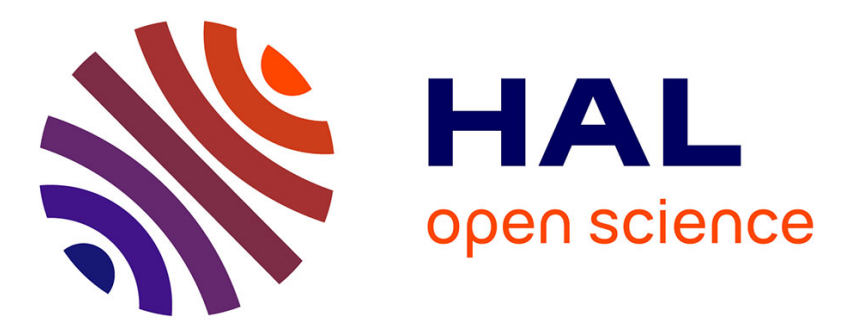

\title{
Proofreading by students: implications of executive and non-executive components of working memory in the detection of phonological, orthographical, and grammatical errors
}

Pascale Larigauderie, Coralie Guignouard, Thierry Olive

\section{To cite this version:}

Pascale Larigauderie, Coralie Guignouard, Thierry Olive. Proofreading by students: implications of executive and non-executive components of working memory in the detection of phonological, orthographical, and grammatical errors. Reading and Writing, 2020, 33, pp.1015-1036. 10.1007/s11145019-10011-6 . hal-02456311

\section{HAL Id: hal-02456311 \\ https://hal.science/hal-02456311}

Submitted on 27 Jan 2020

HAL is a multi-disciplinary open access archive for the deposit and dissemination of scientific research documents, whether they are published or not. The documents may come from teaching and research institutions in France or abroad, or from public or private research centers.
L'archive ouverte pluridisciplinaire HAL, est destinée au dépôt et à la diffusion de documents scientifiques de niveau recherche, publiés ou non, émanant des établissements d'enseignement et de recherche français ou étrangers, des laboratoires publics ou privés. 


\title{
Proofreading by students: Implications of executive and nonexecutive components of working memory in detection of typographical, lexical, or grammatical errors \\ Pascale Larigauderie, Coralie Guignouard, and Thierry Olive Université de Poitiers and CNRS, France pascale.larigauderie@univ-poitiers.fror thierry.olive@univ-poitiers.fr
}

\author{
Centre de Recherches sur la Cognition et l'Apprentissage \\ Bâtiment A5, \\ 5 avenue Théodore Lefebvre \\ TSA 21103 \\ 86073 Poitiers Cedex 9, FRANCE
}

\begin{abstract}
Article publié dans
Larigauderie, P., Guignouard, C. \& Olive, T. (2020). Implication of executive and nonexecutive components of working memory in detection of typographical, lexical, or grammatical errors. Reading \& Writing: An Interdisciplinary Journal. DOI: 10.1007/s11145-019-10011-6.
\end{abstract}

\begin{abstract}
The present research studied the role of the nonexecutive and executive components of working memory in the detection of typographical, lexical, and grammatical errors. Before performing the error detection tasks, undergraduate participants completed a battery of tasks that evaluated nonexecutive functions (verbal and visuospatial storage) and executive functions (coordination of verbal and visuospatial storage and processing, strategic retrieval from long-term memory, effortful shifting) as support working memory. The analyses found that typographical errors were better detected than grammatical errors, followed by lexical errors. Visuospatial storage and coordination of verbal storage and processing were significant predictors of detection of typographical and lexical errors. Effortful shifting was a significant predictor only of detection of lexical errors, while strategic retrieval in long-term memory was the only predictor of detection of grammatical errors. Globally, in the verbal domain, the executive component of working memory appeared more involved than the nonexecutive component whereas, in the visuospatial domain, the nonexecutive component seems more involved than the executive component.
\end{abstract}

Keywords: error detection, working memory, executive functions, short-term storage. 
Being skilled in detecting errors in texts is important in daily life, as it constitutes a critical component in learning to read and write (Chromik, 2002). Proofreading, another term for effectuating such an ability, is a complex cognitive activity involving both languagespecific processes and high-level cognitive processes related to attention and problem solving (Brunyé, Mahoney, Rapp, Ditman, \& Taylor, 2012; Hacker, Plumb, Butterfield, Quathamer, \& Heineken, 1994). Proofreaders must focus their attention at the word level to recognise the correct spelling of words; They also must attend to the syntactic and semantic levels to detect grammatical and/or semantic errors. Past research has shown that the accuracy of error detection is influenced by several factors related to the characteristics of the task and, as well, the individual who detects the errors.

Considering the task characteristics that affect error detection, one of the most important factors in this process is the type of error to be found. Semantic errors, which require the integration of different parts of the text, are less well detected than errors at the word level, such as lexical or typographical errors (for example, see Faigley \& Witte, 1980; Hacker et al., 1994; Levy, Di Persio, \& Hollingshead, 1992; Shafto, 2015). The purpose of the revision in which the individual is engaged has also a direct impact on error detection. For example, when individuals are oriented towards understanding the meaning of the text, the detection of semantic errors is improved (Beal, Bonitatibus, \& Garrod, 1990). How the text is displayed on a computer also affects error detection: Error detection is better when texts are presented page-by-page instead of in a scrolling mode (Piolat, Rousseey, \& Thunin, 1993). Similarly, color variations in displaying the text affect error detection (Piepenbrock, Mayr, \& Buchner, 2014; Szull \& Berry, 1996).

Regarding readers' characteristics, rereading and/or having a greater familiarity with the text improves detection of syntactic, semantic, or typographical errors (Levy, 1983). Levy 
and Begin (1984) suggested that an account in terms of allocation of limited working memory resources between word recognition processes and semantic integration is more relevant than explanations that resort on more efficient visual scanning. They showed that familiarity with the text leads to more fluent reprocessing of its words and meaning, thus freeing resources for the proofreading task (see also Levy, Newell, Snyder, \& Timmins, 1986). Moreover, increased familiarity when proofreading a text generated by the reader results in less efficient error detection than when reading a text that has not been written by the proofreader (Daneman \& Stainton, 1993). However, error detection in a familiar text is not affected by instructions that focus the reader on surface or deep processing of the text (Pilotti, Maxwell, \& Chodorow, 2006).

The age of the reader also accounts for differences in proofreading. In children, poor readers are less accurate in detecting lexical errors than good readers, just as young readers are lower proofreaders than are older children (Supramaniam, 1983). Elderly persons have preserved detection performance for spelling errors and surface errors but, relative to younger individuals, degraded performance in detecting grammatical or semantic errors, as well as errors in the internal consistency of the text. This has been found to be especially true for difficult text passages and when detection depends on the integration of non-adjacent portions of text (Shafto, 2015; Zabrucky, Moore, \& Schultz, 1993). Another individual factor that affects error detection is the greater or lesser stimulation of the central nervous system, in other words, the state of arousal. Caffeine intake, to take an example, increases the rate of detection of global errors, i.e., involving the processing of several words of a sentence such as for incorrect subject-verb agreement or verb tense (Brunyé et al., 2012).

According to Hayes (1996), the differences between individuals in the efficiency of their revision of a text can result from the failure of processes at the basis of the detection (for example, a failure to detect grammatical problems) or of an inappropriate task schema (for 
example, a task schema focused on the detection of 'surface' errors instead of deep processing for detecting semantic errors). However, it may also result from an insufficient availability of their working memory capacity to coordinate the basic revision processes necessary for reading and evaluating the text.

Working memory plays an important role in comprehension of written language (Ardila, 2003; Daneman \& Carpenter, 1980; Juffs, 2004; Leeser, 2007; Miyake \& Friedman 1998; Walter, 2004; Waters \& Caplan, 1996). The models of the writing processes that include working memory rely on Baddeley's (1986) model of the mechanism (Hayes, 1996, 2012; Kellogg, 1996; for a review, see Olive, 2004). In this model, working memory includes two short-term storage registers: the visuospatial sketchpad and the phonological loop (PL) which, respectively, temporarily hold visuospatial and verbal information retrieved from long-term memory or in the environment, but also transient representations from current processing. In addition, a third register, the central executive, which groups together different executive functions, organises the retrieval of information in long-term memory and controls the flow of cognitive activities by distributing resources to the ongoing related processes.

As suggested, text revision involves effortful processes. McCutchen, Francis, and Kerr (1997) have suggested that a significant portion of working memory capacity allocated for revising a text is involved in error detection. Roussey and Piolat (2008) have shown that critical reading, carried out for the purpose of detecting errors in the text, is more effortful than reading to understand the text, and that the cognitive demands of detection in individuals with low working memory capacity vary according to the nature of the errors to detect.

Studies of the role of working memory in error detection generally evidence an involvement of working memory in the detection of errors (see, for example, Piolat, Roussey, Olive, \& Amada, 2004). Adams, Simmons, Willis, and Pawling (2010) showed that only verbal working memory - the PL of working memory - is related to performance in error 
detection (see, however, Evans et al., 2015, who conclude that working memory is not involved in reviewing the structure of sentences and of discourses). Thus, the limited capacity of working memory impacts error detection: Participants with a greater working memory capacity correct more errors than participants with a smaller working memory (Piolat \& Médard, 1998). More generally, the amount of attentional resources required for detection depends on the depth of processing involved in the different types of errors to be detected: the more errors required for an integrative level of processing, the more they place demands on working memory capacity in order to detect them. For instance, the errors whose detection requires processing more than a word (syntactic) or deep processing (semantic errors) require more working memory capacity that lexical and typographical errors, which involve processing only at the word level (Larigauderie, Gaonac'h, \& Lacroix, 1998).

Other studies have investigated the role of the different components of working memory in error detection. The executive center (CE), the visuospatial sketchpad (VSS) and the PL, all processes involved in reading and editing (Kellogg, 1996), are differentially involved in detection of errors at different levels of the text. From this perspective, Larigauderie et al. (1998) have examined the performance of students detecting errors and simultaneously performing additional tasks involving the CE or PL. The errors introduced in the text were typographic (incorrect grapheme and phonologically incorrect letters), spelling errors (lexical or grammatical errors, with incorrect graphemes but with plausible phonology), and semantic errors (omission or addition of words that affected comprehension of the sentence). The detection of typographical errors was not affected by the secondary task which involved articulatory suppression in the PL or the CE (assessed random number generation), whereas detection of syntactic and semantics errors, and to a lesser extent that of spelling errors, was affected by the type of secondary tasks. Moreover, articulatory suppression essentially affected the detection of errors which required processing more than a 
single word: errors that involved processing large spans of words (within or between sentences) required more working memory capacity than errors at the word level. Dedeyan, Olive, and Largy (2006, see also Dedeyan, Largy, \& Negro, 2006) examined the errordetection performance of subject-verb agreement, with participants performing verbal or visual secondary tasks. They showed that less skilled writers (in this case, children) detected fewer errors of subject-verb agreement when performing a verbal secondary task, while performance of more experienced writers (in the study, adults) was degraded only by the visual secondary task. The authors concluded that error detection in novices' writing was based on an algorithmic procedure involving verbal working memory, while more skilled individuals used a visual search procedure (involving the VSS of working memory) to identify in the text the surface characteristics of the morphological agreements.

The objective of the present research was to study the role of the three components of working memory (CE, PL, and VSS) in error detection, considering the fractionation of the executive center of working memory in different executive functions (cf. Friedman \& Miyake 2004; Miyake et al., 2000). Following the approach and findings of Fournier-Vicente, Larigauderie, and Gaonac'h (2008), we investigated the following executive functions: coordination between storage and processing of verbal information, coordination between storage and processing of visuospatial information, controlled access to long-term memory, mental flexibility, and selective attention. We focused on error detection, so participants' skills for correcting errors were only considered through control variables.

The study used a naturalistic paper-and-pencil proofreading task, with an experimental design consisting of isolating each type of error in a different text. Successive detection tasks were proposed to the participants, according to the nature of the errors introduced into the text: typographical errors, lexical errors and detection of grammatical errors. Before participants completed the error detection tasks, a battery of working memory 
tasks was administered, in order to evaluate the different executive and nonexecutive 'abilities' of their working memory. The objective of the present study was to investigate to what extent differences in detection of different types of errors were related to differences in executive and nonexecutive functions of working memory.

\section{Method}

\section{Participants}

Forty volunteers ( 23 women), aged 17 to 51 years $(M=21, S D=5$ years 4 months) took part in the experiment. All the participants were native French speakers and were studying at the University of Poitiers. The average length of their schooling was 14 years 2 months $(S D=1$ year 10 months, minimum $=12$ years, maximum $=20$ years $)$.

\section{Tasks and Materials}

\section{Error detection tasks.}

Three text extracts adapted from the novel Temps mort by Harlan Coben (2008) were used for the detection tasks. Each text was about 300 words and was presented on an A4 sheet of paper. Twenty errors were introduced within each text, in random locations. The instructions given to the participants elaborated the nature of the errors to be detected: typographical (typing errors), lexical or spelling errors (misspelled words), or grammatical errors (i.e., gender and number agreement or misuse of past participles and infinitives). The participants were informed that they were to read the texts and underline the errors they could identify (without correcting them). The instructions specified that the participants should read the text only once, thus not reading it back, unless it turned out to be necessary to verify the presence of an error. For each detection task, the dependent measures were the number of detected errors, the number of false detections, and the detection time (in seconds).

Typographical error detection task. The text used for the detection of typographical errors consisted of 298 words distributed on 20 lines (see Supplementary Material [SM] 1). 
The 20 typographical errors corresponded to errors in the succession of letters (letter migrations, letter omissions, and letter commissions, 'toujousr' for 'toujours') which resulted in incorrect phonology.

Lexical error detection task. The text with lexical errors consisted of 302 words distributed on 21 lines (see SM 2). The 20 lexical errors corresponded to errors in the correct spelling of words (inappropriate or omitted double consonant, letter substitutions, letter omissions, and other incorrect spelling forms, e.g., 'essentiellemment' for 'essentiellement', 'vulguère' for 'vulgaire') which did not affect phonology.

Grammatical error detection task. The text with grammatical errors consisted of 302 words distributed on 20 lines (see SM 3). There were 20 grammatical errors, which resulted from a failure to apply grammatical rules. The introduced errors were misuse of past participle form; errors of number; or gender agreement error, for example 'des tas de gosses [...] qui attendait' for 'attendaient' (lots of kids [...] waiting). In addition, 10 grammatical errors concerned an agreement between successive words - local grammatical errors, for example 'des valeur' for 'des valeurs' (values); the remaining 10 errors concerned agreement between distant words in the text - distant grammatical errors, for example, 'l'animosité curieuse dont il avait été l'objet à l'époque n'avaient rien de commun' for 'avait' (the curious animosity of which he had been the object at the time had nothing in common).

Error correction task. To estimate the participants' skill in correcting the introduced errors, they were asked to a proofread another text containing all the errors presented in the detection tasks. In this text, printed on a A4 sheet of paper with a 24-point line spacing, all the errors were underlined (see SM 4). The corrections had to be written below the underlined words. If the participants did not know the correct form, they were invited to draw a cross under the word. The dependent measure was the number of correctly corrected errors. 
Reading comprehension task. This task aimed at determining the reading time of every participant of a brief text, read silently with the objective of understanding it. To encourage comprehension of the text, the participants were informed that two questions concerning the text contents would be posed immediately after their reading. Participants were instructed to adopt their usual reading speed. A text of 127 words was presented (see SM 5). Reading times (in seconds) were recorded for each participant.

\section{Nonexecutive working memory tasks (short-term storage).}

To assess the storage capacity of working memory, we used two simple span tasks adapted from Fournier-Vicente et al. (2008) involving verbal or visuospatial storage. More detailed information about these tasks is presented in SM 6.

Forward verbal storage task (digit span test). The participants were presented orally a series of digits they had to recall in the same order to their presentation. Digits were presented in sets of two to nine digits. There was no time limit for recall. The dependent measure was the number of correctly (correct word in correct order) recalled series.

Forward location storage task (location span test). The participants were presented with a $5 \times 5$ matrix on a computer screen in which increasingly long series of locations were sequentially presented. Immediately after each sequence presentation, the participants had to reproduce the sequence in the same order. The test consisted of sets from two to nine locations. The dependent measure was the number of correctly recalled sequences (in the same order of their presentation).

\section{Executive working memory tasks (executive functions).}

All the participants completed 10 tasks in this domain. The objective here was estimating five target executive functions, whose dissociation was studied by FournierVicente et al. (2008): verbal storage-and-processing coordination (backward digit span task and verbal transposed span task); visuospatial storage-and-processing coordination (backward 
location span task and visuospatial transposed span task); strategic retrieval in long-term memory (semantic verbal fluency task and random letter generation task); selective attention (Stroop numerical test and $\mathrm{d} 2$ target detection task); and shifting (plus-minus task and Trail Making Test). These tasks are classically used in cognitive psychology and neuropsychology studies and/or in clinical practice to evaluate executive functioning. More detailed information about these tasks is presented in SM 6.

Backward digit span task. The method, type of material, and measures used for this task are identical to the forward verbal storage task, with two exceptions: Participants had to recall the series of digits in the opposite order of their presentation. The task consisted of 18 series, three for each set size (from two to seven digits).

Verbal transposed span task. This task is identical to the forward verbal storage task with two exception: after each list, a ' +1 ' or ' -1 ' appeared on the screen indicating that the participant had to mentally add/subtract the numeral 1 to/from each of the list's digits, before recalling the resulting series in correct serial order. The test consisted of 18 series, three for each set size (from two to seven digits).

Backward location span task. This task is identical to the forward location task except that the participants had to reproduce the sequence of locations in the opposite order to their presentation and that the test consisted of 18 series, three for each set size from two to seven digits.

Visuospatial transposed span. This task is identical to the forward location task with two exceptions. First, immediately after each sequence, a left-pointing or a right-pointing arrow appeared at the bottom of the empty matrix to indicate whether the participant had to move the whole sequence of locations one row to the left or right, while keeping them in the initial order of presentation. Second, the test consisted of 18 series, three for each set size from two to seven digits. 
Semantic verbal fluency task. This task relies on the general capability to strategically search and retrieve information from long-term memory. The participants were given one minute to generate aloud as many words as possible belonging to the animal category. The dependent measure was the number of produced animal names minus the number of repetitions and intruders.

Random letter generation task. The participants had to produce a random sequence of letters (one letter per second with a total of 100 letters). The random sequences produced were analysed using Towse and Neil's (1998) RgCalc program, which computes various 'randomness' indices. A set of randomness indices was calculated and we used a PCA to reduce the data. The obtained four-factor solution replicated Towse and Neil's results and indicated that indices reflecting the ability to monitor retrieval strategies loaded on Factor 1. Consequently, the factor scores for this factor were used as the dependent variable.

Trail Making Test (adapted from Reitan \& Wolfson, 1985). The task of the participant was to draw lines as quickly as possible to connect circled numbers (1 to 12) and letters (A to L) in part A and by alternating numeric and alphabetic sequence (i.e., 1-A-2-B, etc.) in part B. We collected execution times and used the B/A ratio to assess the shift cost.

Plus-minus task (adapted from Spector \& Biederman, 1976). In this task, the participants were presented with three lists of two-digit numbers. They were instructed to add 3 to each number on the first list and to subtract 3 from each number on the second list. On the third list, the participants had to alternate between adding 3 to and subtracting 3 from the numbers. The dependent measure was the shift cost calculated as an execution time ratio between the time to complete the alternating list and the average of the times to complete the first two lists with no shift.

The Stroop numerical test (adapted from Stroop, 1935). In this version of the Stroop

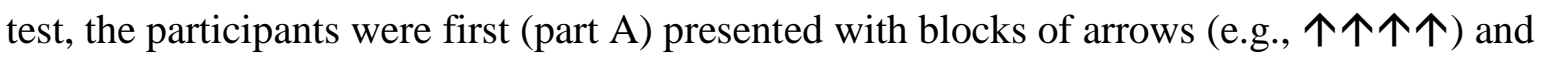


were instructed to say aloud the number of arrows in each block. In part B, they were presented with rows of digits whose value varied from 2 to 5 and were instructed to read aloud the digits. Finally, in Part C, the stimuli consisted of digits presented in blocks of similar digits (e.g., 2222). The participants had to say aloud the number of digits in each block, irrespective of the value of the digits. The dependent measure was the execution time ratio between Part $\mathrm{C}$ and Part $\mathrm{A}$.

The d2 target detection task (Brickenkamp, 1998). This test is considered a measure of selective attention (Brickenkamp \& Karl, 1986, quoted from the French manual of the d2 task, ECPA, 1998). In this paper-and-pencil task, the participants were asked to cross out as fast and accurately as possible target signs randomly distributed among distractors. The dependent measure was the total number of signs examined minus the total number of errors and omissions.

\section{Procedure}

The participants were tested individually in two sessions of approximately 40 minutes each. During the first session, the experimenter collected information about the participants. The order of task administration was fixed for all participants to make sure the task order did not generate differences across subjects that were not due to their own characteristics. The testing order in Session 1 was as follows: Stroop numerical, the backward digit span, visuospatial transposed span, forward location storage, verbal transposed span, and backward location span. The testing order in Session 2 was as follows: Trail Making, random letter generation, $\mathrm{d} 2$ target detection, plus-minus, semantic verbal fluency, forward verbal storage, reading comprehension, error detection, error correction. The order of realisation of the three error detection tasks was counterbalanced across participants.

\section{Results}

\section{Performances in Error Detection and Correction}


Descriptive statistics are presented in Table 1. Most of the variables showed a satisfactory level of normality with skewness values less than 2 and kurtosis values less than 4 (Kline, 1998, reported by Kane et al., 2004), except for the false detection of typographical and grammatical errors, and for the typographical and grammatical correction measures.

Table 1

Descriptive Statistics for the Detection, Reading, and Correction Tasks $(N=80)$

\begin{tabular}{lcccccc}
\hline Variables & Mean & SD & Min & Max & Skewness & Kurtosi \\
\hline Reading-comprehension time & 44.95 & 8.99 & 24.47 & 69.00 & -0.0350 & -0.0949 \\
Error detection time & & & & & & \\
$\quad$ Detection time TYP (s) & 118.03 & 32.79 & 57.00 & 25.30 & 1.1462 & 3.4830 \\
$\quad$ Detection time LEX (s) & 159.00 & 42.64 & 86.35 & 340.00 & 1.2428 & 3.6936 \\
$\quad$ Detection time GRAM (s) & 159.13 & 45.49 & 84.88 & 350.00 & 1.3428 & 3.5900
\end{tabular}

Number of detected errors

$\begin{array}{lcccccc}\text { TYP }(/ 20) & 16.19 & 2.29 & 9 & 20 & -0.3596 & 0.0738 \\ \text { LEX }(/ 20) & 10.78 & 3.81 & 2 & 18 & -0.3135 & -0.5027 \\ \text { GRAM }(/ 20) & 13.74 & 4.00 & 4 & 20 & -0.6015 & -0.3200 \\ \quad \text { Local GRAM }(/ 10) & 7.17 & 2.13 & 1 & 10 & -0.9063 & 0.5847 \\ \quad \text { Distance GRAM }(/ 10) & 6.70 & 2.23 & 2 & 10 & -0.3985 & -0.7205\end{array}$

Number of false detections

$\begin{array}{lllllll}\text { TYP } & 0.06 & 0.37 & 0 & 3 & 7.0385 & 53.5981 \\ \text { LEX } & 1.15 & 1.41 & 0 & 6 & 1.4076 & 2.0110 \\ \text { GRAM } & 1.25 & 1.31 & 0 & 7 & 1.5430 & 4.0267\end{array}$

Number of correctly corrected errors

$\begin{array}{lllllll}\operatorname{TYP}(/ 20) & 19.64 & 0.77 & 16 & 20 & -2.7218 & 8.3104 \\ \operatorname{LEX}(/ 20) & 17.05 & 2.36 & 11 & 20 & -0.6619 & -0.4998\end{array}$




$\begin{array}{lllllll}\text { GRAM }(/ 20) & 19.09 & 1.46 & 13 & 20 & -2.35824 & 5.8259 \\ \text { Locales GRAM (/10) } & 9.64 & 0.56 & 8 & 10 & -1.2457 & 0.6211 \\ \text { Distances GRAM (/10) } & 9.40 & 1.24 & 3 & 10 & -2.8596 & 9.6323\end{array}$

Note. TYP: Typographical errors; LEX: Lexical errors; GRAM: Grammatical errors

A nonparametric-Friedman test of differences among repeated measures of error correction revealed a chi-square value of 86.86, which was significant, $p<.00001, N=80, d f$ $=2$. A Wilcoxon signed-ranks test indicated that lexical errors correction was statistically significantly lower than typographical errors correction, $Z=6.88, p<.00001$, and grammatical errors correction, $Z=6.54, p<00001$. The correction of grammatical errors was statistically significantly lower than that of typographical errors, $Z=3.55, p=.0004$. An analysis of variance with type of errors as within-subject factor indicated that the average detection time significantly varied according to the nature of the errors, $F(2,158)=124.53, p$ $<.001, \eta p^{2}=0.61$. The detection time was lower for the typographic than for the lexical, $F(1$, $79)=190.73, p<.001$, and grammatical errors, $F(1-79)=186.46, p<.001$, the difference between the lexical and grammatical errors being not significant, $F<1$.

As indicated by the standard deviations, there were relatively important interpersonal differences of reading time, detection time, and of spelling skills. Additional indicators were therefore calculated to integrate the correction performance of the participants. We calculated the detection performance only for errors the participant knew the exact correction (detection rate of corrected errors $=$ number of detected and corrected errors $/$ number of corrected errors; omissions $=$ number of correctly corrected but not detected errors). We also calculated detection efficiency (number of detected errors per minute) and examined the detection cost after controlling for reading time (detection time/reading time). Table 2 presents the mean scores and standard deviations on these indicators for each type of errors. 
Mean Scores (and Standard Deviations) in Detection of Errors for Each Type of Error

Errors

Variables

TYPO LEX

GRAM

Detection rate of corrected errors (number of

detected and corrected errors / number of corrected

errors)

$0.82(0.11) \quad 0.58(0.18)$

$0.69(0.19)$

Efficiency (number of detected errors per minute)

$$
8.84(2.80) \quad 4.48(2.27) \quad 5.55(2.20)
$$

Omissions (number of accurately corrected but not

detected errors)

$3.56(2.25) \quad 6.94(2.50)$

Detection cost (detection time / reading time)

Note. TYP: Typographical errors; LEX: Lexical errors; GRAM: Grammatical errors

A series of one-way ANOVAs with type of errors (typographical, lexical, and grammatical) as a within-subject factor was conducted on each of these variables. The detection rate of corrected errors depended significantly on the type of error, $F(2,158)=$ 55.32, $p<.00001, \eta \mathrm{p}^{2}=0.41$. Post-hoc comparisons with the Bonferroni procedure $(p<$ .016) indicated that the detection rate was significantly higher for the typographical errors than for the lexical errors, $F(1,79)=109.41$; for the grammatical errors, $F(1,79)=27.44$; the detection rate of the lexical errors was significantly lower than that of the grammatical errors, $F(1,79)=28.35$. The detection rate of corrected grammatical errors did not significantly differ for the local errors $(M=0.72, S D=0.21)$ or for the global errors, $M=0.69, S D=0.22$, $t(79)=1.30, p=.19$. Efficiency of detection also varied according to the type of error, $F(2$, $158)=167.35, p<.00001, \eta p^{2}=0.68$. Efficiency for typographical errors was significantly higher than for lexical errors, $F(1,79)=294.72$, and for grammatical errors, $F(1,79)=$ 125.53, lexical errors being significantly lower than grammatical ones, $F(1,79)=33.30, p_{s}<$ 
.016 (Bonferroni procedure). The number of omissions during detection (errors which the participant corrected accurately during the correction phase but did not detect in the detection phase) also varied with the type of error, $F(2,158)=36.52, p<.00001, \eta p^{2}=0.32$.

Omissions were significantly lower for the typographical than for the lexical errors, $F(1,79)$ $=86.24)$ or the grammatical ones, $F(1,79)=24.55$, omissions being significantly higher for lexical errors than for grammatical ones, $F(1,79)=9.22, p_{s}<.016$, Bonferroni procedure. Finally, the detection cost also varied with the type of error, $F(2,158)=137.04, p<.00001$, $\eta p^{2}=0.63$. Detection cost was significantly lower for typographical errors than for lexical errors, $F(1,79)=210.21$, or grammatical ones, $F(1,79)=193.43, p_{\mathrm{s}}<.016$, Bonferroni procedure, but did not differ between lexical and grammatical errors, $F(1,79)<1$.

In sum, the participants presented the lowest performance for detecting lexical errors and the best performance with typographical errors, with intermediate performance for detecting grammatical errors.

\section{Performances on the Working Memory Tasks}

Descriptive statistics for working memory measures are presented in Table 3. All the variables showed a satisfactory level of normality, with skewness values less than 2 and kurtosis values less than 4 (Kline, 1998, reported by Kane et al., 2004). The executive performances are consistent with those reported in the literature for young adults in studies using similar tasks (see Fournier-Vicente et al., 2008).

\section{Table 3}

Descriptive Statistics for Working Memory Measures ( $\mathrm{N}=80)$

\begin{tabular}{lllllll}
\hline WM functions & Standard & & & & \\
Tasks (variables) & Mean & deviation & Min & Max & Skewness & Kurtosis \\
\hline
\end{tabular}


- Nonexecutive tasks

Verbal storage

Forward verbal storage

$14.86 \quad 2.51$

8

21

0.1104

0.1018

(number of recalled series)

Visuospatial storage

Location storage (number of

$11.09 \quad 2.04$

$4 \quad 18$

0.2249

$-0.0126$

recalled series)

- Executive working memory tasks

Coordination of verbal storage-and-processing (number of recalled series)

$\begin{array}{lllllll}\text { Backward digit span } & 10.35 & 2.55 & 5 & 16 & 0.3136 & -0.3980 \\ \text { Verbal transposed span } & 10.96 & 2.36 & 6 & 16 & 0.0817 & -0.7103\end{array}$

Coordination of visuospatial storage-and-processing (number of recalled series)

Backward location span

11.36

2.17

$6 \quad 16$

0.0204

$-0.2322$

Visuospatial transposed span

8.50

2.64

$1 \quad 14$

$-0.0996$

0.1246

Strategic retrieval

Semantic verbal fluency

22.46

4.81

12

41

0.6706

1.9349

(number of correct items)

Random letter generation

0

1

$\begin{array}{ll}-1.98 & 2.87\end{array}$

0.3192

$-0.0999$

(factor scores)

Shifting

Plus-minus (ratio score)

1.30

0.21

0.91

2.10

0.8388

1.2981

Trail Making Test (ratio score)

1.94

0.61

0.97

4.50

1.8365

3.4409

Selective attention

Stroop numerical test (ratio

1.31

0.19

1

1.93

1.0406

1.2578

score) 


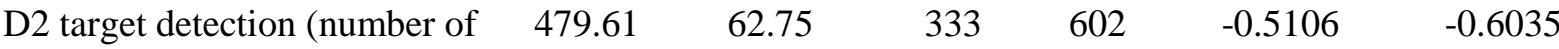
signs correctly processed)

\section{Principal Components Analysis of Executive Measures}

To use a unique indicator for each of the considered executive functions, we conducted a principal component analysis (PCA), which reduces a large number of variables to a smaller number of components. Thus, the 10 variables (for the five target functions) were included in the PCA. The correlations between the variables are presented in Table A, SM 7.

Significant correlations within executive functions were obtained for the performances between the two tasks involving coordination of storage and processing in the verbal domain $(r=.61)$ and in the visuospatial domain $(r=.59)$, between the two tasks involving strategic retrieval in long-term memory $(r=.41)$, but not between the two tasks involving shifting $(r=-.02)$ or selective attention $(r=.10)$.

Correlations between functions were significant between coordination of verbal and of visuospatial storage and processing tasks $(r=.24$ for the correlation between backward tasks; $r=.33$ for the correlation between transposed span tasks), but these correlation coefficients were more modest than those observed within each coordination function. A significant negative correlation between the Trail Making Test and the visuospatial backward span and transposed span ( $r=-.24$ and $r=-.31$, respectively), as well as a significant positive correlation between the $\mathrm{d} 2$ task and the visuospatial transposed span $(r=.32)$, were observed.

A PCA was applied to these data. The first criterion taken into consideration to determine the number of factors to extract was the Kaiser-Guttman rule (Kaiser, 1960), which excludes factors with eigenvalues less than 1 . This first criterion led to a four-factor solution. Considering the relatively modest size of our sample, we then run several factorial analyses, each with one to four factors, and we examined the corresponding residual correlations 
matrix to estimate the adequacy of each solution (cf. Gorsuch, 1983; Tabachnick \& Fidell, 2001). The four-factor solution adequacy was confirmed by comparison of the correlation matrix of the residuals of each solution (of one-factor solution to four-factor solution, see Table B, SM 7). This four-solution retained is presented in Table A SM 8 (eigenvalues and percentage of explained variance) and in Table B SM 8 (eigenvalues and loadings after varimax orthogonal rotation).

Factor 1 was highly loaded by the backward visuospatial span task (0.83) and the transposed visuospatial span task (0.86), and to a lesser extent by the Trail Making Test interference score (-0.49). The characteristic shared by the two first tasks was the ability to simultaneously maintain and manipulate visuospatial information. This ability can also be implemented in the Trail Making Test (items being spatially distributed on a A4 sheet, a good capacity of storage and processing coordination of visuospatial material can lead to a lower interference in the task shifting situation). Factor 2 was highly loaded by the random generation task ( 0.73 , ability to produce a good random sequence) and by the fluency verbal task $(0.83$, ability to produce a large number of responses in accordance with the task instructions) and, to a lesser extent, by the Trail Making Test interference score (0.46). The characteristic shared by the two first tasks is the strategic retrieval ability (controlled access to information in long term memory). This ability can also be implemented in the Trail Making Test (as far as the simultaneous preservation of the access to the representations of the order of digits and the alphabetical order can create a high interference in the task shifting situation). Factor 3 was highly loaded by the interference score on the plus-minus task $(0.70)$, that requires shifting between mental sets; by the interference score on the Stroop task $(0.65)$, that requires selective attention and prepotent response inhibition; and, to a lesser extent, by the productivity score on the $\mathrm{d} 2$ task $(0.56)$, that requires concentrative attention and selective attention as well, without prepotent response inhibition. The $\mathrm{d} 2$ task is classically used to 
assess selective attention ability in visual modalities (Lezak, 1983) but, according to Spreen and Strauss (1998), the task can be also used to assess the difficulty in response shifting. This factor may therefore represent the effort related to shifting between tasks or mental sets. This factor is also associated with selective attention and failure in inhibiting irrelevant dominant responses and with sustained attention ability. It has to be noticed that the correlation between the selective attention component and the shifting component was also relatively high in Fournier-Vicente et al.'s (2008) study (the correlation between both latent variables was .59). Factor 4 was highly loaded by the backward verbal span task (0.90) and the transposed verbal span task (0.84). The characteristic shared by these two tasks was the ability to simultaneously maintain and manipulate some verbal information.

Consequently, to analyse the relations between working memory capacities and error detection performances, the factorial scores of Factors 1 to 4 were used as indicators of the studied executive capacities, respectively, 'visuospatial storage and processing coordination' (factorial scores on Factor 1 PCA, higher values indicate better efficiency), 'strategic retrieval in LTM' (factorial scores on Factor 2 PCA, higher values indicate better efficiency), 'effortful shifting' (factorial scores on Factor 3 PCA, higher values indicate lower shifting efficiency), and 'verbal storage and processing coordination' (factorial scores on Factor 4 PCA, higher values indicate better efficiency).

\section{Working Memory Capacity and Error Detection}

The relationships between error detection performances and working memory scores were first correlated. Regarding the correlations between the different aspects of working memory (see Table A SM 9), there was a significant correlation between executive and nonexecutive performance in the verbal domain (correlation between performance at the forward verbal storage task and factorial score related to coordination of verbal storage and processing: $r=.67$ ), as well as in the visuospatial domain (correlation between performance at 
the forward storage task and factorial score related to coordination of visuospatial storage and processing: $r=.67)$.

Concerning the correlations between the various indicators of error detection (see Table B SM 9), a significant negative relationship was observed between the detection rate of corrected lexical errors and the detection time $(r=-.27$ for the time related only to detection of lexical errors). The correlation was not significant for the other types of errors. For each type of error, the higher the detection time, the lower the efficiency, $p_{\mathrm{s}}<.01$. These relations remained significant when controlling for reading time with the variable 'detection cost'.

The significant correlations between the detection of typographic errors and the working memory scores (see Table C SM 9) showed that the higher the visuospatial storage, the higher the detection rate of typographical errors $(r=.23)$. On the other hand, the higher the visuospatial storage, the longer the duration of the detection $(r=.35)$. As a result, the higher the visuospatial storage, the lower the efficiency $(r=-.25)$. In addition, the higher the performance of coordination of visuospatial storage and processing, the higher the cost of detection $(r=.23)$. Similarly, the higher the strategic retrieval in long-term memory, the higher the rate for detecting known errors $(r=.22)$.

Concerning the detection of lexical errors (see Table C SM 9), the higher the effortful shifting factor - i.e., the lower the shifting ability - the higher the detection rate of corrected lexical errors $(r=.23)$. It should also be noted that the higher the coordination of verbal storage and processing, the shorter the detection time $(r=-24)$. As a result, there was a significant positive relationship between efficiency and coordination of verbal storage and processing $(r=.29)$. The efficiency of detection was also significantly and positively correlated with the effortful shifting factor $(r=.31)$ but was negatively related with visuospatial storage capacities $(r=-.29)$. 
Regarding the detection of grammatical errors (see Table C SM 9), the higher the verbal storage, the shorter the detection time $(r=-.30)$. Likewise, the higher the performance for coordinating verbal storage and processing, the shorter the detection time $(r=-27)$. Efficiency was positively correlated with verbal storage $(r=.29)$, coordination of verbal storage and processing $(r=.30)$, and strategic retrieval in long-term memory $(r=.32)$.

The relationship between working memory scores and error detection performance has been further investigated using linear mixed-effects model analyses. For these analyses, we categorised the errors in two groups related to the level of processing required to detect the error: local errors (typographical and lexical errors) that require the processing of a single word versus global errors (grammatical errors) that require the processing of several words in a sentence. We first analysed the efficiency of error detection with a linear mixed-effects model with level of errors, verbal storage, visuospatial storage, coordination of verbal storage and processing (factorial scores on Factor 4 PCA), coordination of visuospatial storage and processing (factorial scores on Factor 1 PCA), strategic retrieval in long-term memory (factorial scores on Factor 2 PCA), effortful shifting (factorial scores on Factor 3 PCA) as fixed effects, and participants as random effect. Table 4 presents the results of this first analysis (Model 1), including all the predictors. Several different regression models were then tested, each involving an interaction between the level of error and a working memory component (the detailed results of each of the models are presented in Appendix 1, Models $1 \mathrm{~A}$ to $1 \mathrm{~F})$.

Table 4 Regression Analyses Predicting Efficiency in Error Detection (Number of Errors Detected per Minute) from Executive and Nonexecutive Working Memory Measures and Level (Local or Global) of Errors 


\begin{tabular}{lllll}
\hline Variables & $B$ & $t(73)$ & $F(1,73)$ & $p$ \\
\hline Verbal storage & -0.01 & -0.08 & 0.01 & .94 \\
Visuospatial storage & -0.19 & -2.07 & 4.30 & .04 \\
Coordination of verbal storage & 0.71 & 2.55 & 6.52 & .01 \\
and processing & & & & .58 \\
Coordination of visuospatial & 0.15 & 0.55 & 0.30 & \\
storage and processing & & & & .015 \\
Strategic retrieval in LTM & 0.51 & 2.49 & 6.18 & .04 \\
Effortful shifting & 0.42 & 2.06 & 4.26 & $<.0001$ \\
Errors (local versus global) & -0.55 & $t(79)=-5.28$ & $F(1-79)=27.88$ & \\
\hline Note. Verbal storage: number & & & & \\
\hline
\end{tabular}

Note. Verbal storage: number of recalled series at the backward digit span task; Visuospatial storage: number of recalled series at the location storage task; Coordination of verbal storage and processing: factorial scores on Factor 4 PCA; Coordination of visuospatial storage and processing: factorial scores on Factor 1 PCA; Strategic Retrieval in LTM: factorial scores on Factor 2 PCA; Effortful shifting: factorial scores on Factor 3 PCA; Local errors: detections requiring the processing of a single word, i.e., typographical and lexical errors; Global errors: detections requiring the processing of several words in a sentence, i.e., grammatical errors

The first model showed five significant predictors: visuospatial storage $(t=-2.07, B=$ $-0.19, p=.04)$; coordination of verbal storage and processing $(t=2.55, B=0.71, p=.01)$; strategic retrieval in long-term memory $(t=2.49, B=0.51, p=0.015)$; effortful shifting $(t=$ $2.06, B=0.42, p=.04)$; and the level of error $(t=5.28, B=-0.55, p<.0001)$. There was no significant interaction between the level of error and verbal storage, $F(1,78)=1.68, p=.20$ (see Appendix 1, Model 1A); coordination of verbal storage and processing, $F(1,78)=0.11$, $p=.73$ (see Appendix 1, Model 1C); coordination of visuospatial storage and processing, $F(1$, $78)=0.02, p=.89($ see Appendix 1 , Model 1D; or effortful shifting, $F(1,78)=0.41, p=.52$ 
(see Appendix 1, Model 1F). By contrast, the interaction between the level of error and visuospatial storage added to Model 1 brought additional significant predictions, $F(1,78)=$ 4.53, $p=.04$ (see Appendix 1, Model 1B). The interaction between the level of error and strategic retrieval in long-term memory also significantly contributed to the model, $F(1,78)=$ 4.45, $p=.04$ (see Appendix 1, Model 1E).

To further study the significant interactions between the level of errors (local vs. global) and the working memory components related to visuospatial storage and strategic retrieval in long-term which appeared significant in the linear mixed-effects regressions, we conducted complementary regression analyses that examined the implication of working memory in efficiency for detecting the different types of errors (typographical, lexical, and grammatical). The tested models are presented in Table 5.

\section{Table 5}

Regression Analyses Predicting Efficiency in Error Detection (Number of Errors Detected per Minute) from Executive and Nonexecutive Working Memory Measures, for the Detection Task of Typographical, Lexical, and Grammatical Errors

\begin{tabular}{|c|c|c|c|c|c|c|c|c|c|}
\hline \multirow{2}{*}{$\begin{array}{l}\text { Detection } \\
\text { task }\end{array}$} & \multicolumn{3}{|c|}{ Typographical errors } & \multicolumn{3}{|c|}{ Lexical errors } & \multicolumn{3}{|c|}{ Grammatical errors } \\
\hline & \multicolumn{3}{|c|}{ Model 2} & \multicolumn{3}{|c|}{ Model 3} & \multicolumn{3}{|c|}{ Model 4} \\
\hline Variables & $B$ & $t(73)$ & $F(1,73)$ & $B$ & $t(73)$ & $\mathrm{F}(1$, & $B$ & $t(73)$ & $\mathrm{F}(1$, \\
\hline & & & & & & 73) & & & 73) \\
\hline V-S & -0.14 & -0.89 & 0.79 & -0.06 & -0.50 & 0.24 & 0.09 & 0.69 & 0,48 \\
\hline$V S P-S$ & -0.38 & $-2.83^{* *}$ & $6.72 * *$ & -0.24 & $-2.38 *$ & $5.68^{*}$ & -0.7 & -0.70 & 0,50 \\
\hline V-Coord & 1.04 & $2.59 *$ & $2.79 *$ & 0.78 & $2.51 *$ & $6.27^{*}$ & 0.51 & 1.66 & 2,76 \\
\hline VSP-Coord & 0.66 & 1.67 & 1.57 & 0.13 & 0.43 & 0.18 & -0.09 & -0.31 & 0,10 \\
\hline SR-LTM & 0.38 & 1.25 & 6.18 & 0.32 & 1.41 & 1.98 & 0.68 & $2.97 * *$ & $8,81 * *$ \\
\hline
\end{tabular}


Note. ${ }^{*}=p<.05 ; * *=p<.01 ; \mathrm{V}-\mathrm{S}$ : Verbal Storage, number of recalled series at the backward digit span task; VSP-S: Visuospatial storage, number of recalled series at the location storage task; V-Coord: Coordination of verbal storage and processing, factorial scores on Factor 4 PCA; VSP-Coord: Coordination of visuospatial storage and processing, factorial scores on Factor 1 PCA; SR-LTM: Strategic Retrieval in long-term memory, factorial scores on factor 2 PCA; SHIFT-E: Effortful Shifting, factorial scores on Factor 3 PCA

Model 2 showed two significant predictors of detection of typographical errors: visuospatial storage, $t=-2.83, B=-0.38, p=.0061$, and coordination of verbal storage and processing, $t=2.59, B=1.04, p=.0115$. Model 3 showed that these same two predictors were also significant for the detection of lexical errors (respectively, $t=-2.38, B=-0.24, p=$ .0197 and $t=2.51, B=0.78, p=.0145)$, with a third predictor: effortful shifting, $t=3.06, B=$ $0.69, p=.0031$. Model 4 showed a single significant predictor for the detection of grammatical errors, strategic retrieval from long-term memory, $t=2.97, B=0.68, p=.0041$.

Finally, in order to estimate the consequences of the introduction of error correction measures (i.e., language skills) on the results, we introduced in each of the different models the correction score for each type of error. When the number of correctly corrected typographical errors was added to Model 2, it was not significant, $F(1,72)=0.004, p=.95$, and this did not change the significance of the other predictors. When the number of correctly corrected lexical errors was added to Model 3, it added a significant part of the explained variance, $F(1,72)=41.68, p<.0001$, and the significance of the other predictors remained unchanged. When the number of correctly corrected grammatical errors was added to Model 4 , it also added a significant part of explained variance, $F(1,72)=25.37, p<.0001$, and the significance of strategic retrieval in long-term did not change. Accordingly, the participants' 
linguistic skills did not affect the significance of the working memory components that predicted performance in error detection and were an additional predictor of detection of lexical and grammatical errors, but not of typographical errors.

\section{Discussion}

The objective of this research was to study the role of the executive and nonexecutive functions of working memory in detection of different types of errors. For this purpose, we used a battery of working memory tasks and asked participants to detect different types of errors, each type of error being isolated in a different text. We analysed and compared the participants' working memory scores and error detection performances to establish to what extent the differences in detection performance were related to differences in working memory functions.

The results of the analyses carried out on the performances in detection of errors are consistent with previous results in the literature: Performance in error detection varies according to the nature of the errors introduced in the texts. For instance, the detection rate was significantly higher for typographical errors, followed by grammatical errors, with detection rate of lexical errors being the lowest.

The same results were observed in efficiency of detection and failure of detection (omissions): Detection efficiency was higher (with fewer omissions) on typographic errors than on grammatical errors, and efficiency on grammatical errors was higher than on lexical errors. This result supports previous findings (Faigley \& Witte, 1980; Hacker et al., 1994; Hargis et al., 2017; Larigauderie et al., 1998; Levy \& Begin, 1984; Levy, Di Persio, \& Hollingshead, 1992; Levy \& Marek, 1999; Levy, Newell, Snyder, \& Timmins, 1986; Shafto, 2015) showing that errors whose detection requires low-demand processing, such as those required for detecting typographical errors, are better detected than errors whose detection is accompanied by higher-demand processing. 
A principal component analysis on performances of the participants on the working memory tasks identified four executive-related factors: coordination of verbal storage and processing, coordination of visuospatial storage and processing, strategic retrieval in longterm memory, and effortful shifting. The emergence of the first three factors is consistent with the latent variables confirmed by Fournier-Vicente et al. (2008). The last factoreffortful shifting -brings together two latent variables that were dissociated in FournierVicente et al.'s (2008) study: flexibility and selective attention.

The different executive and nonexecutive components of working memory were found to be significantly related, both in the verbal domain (correlation between forward verbal span and coordination of verbal storage and processing) and in the visuospatial domain (correlation between the visuospatial location task and coordination of visuospatial storage and processing). This is consistent with previous studies that reported significant, albeit moderate, correlations between forward and backward simple span tasks with verbal (e.g., Gignac, Kovacs, \& Reynolds, 2018, 1997; Jung, 2018) or visuospatial material (e.g., Kessels, van den Berg, Ruis, \& Brands, 2008).

Based on the four executive factors, as well as the considered nonexecutive components (verbal and visuospatial short-term storage), we analysed the relationships between the participants' different working memory scores and their detection performance. In terms of detection of typographic errors, the detection rate was positively correlated with visuospatial storage and strategic retrieval in long-term memory, while duration and efficiency of detection were negatively correlated with visuospatial storage. Concerning detection of lexical errors, the detection rate and the efficiency rate were positively related with effortful shifting: The higher the effortful shifting factor - that is to say, a low shifting ability - the higher the detection rate and the efficiency of lexical errors. Efficiency for detecting lexical errors was also negatively correlated with visuospatial storage and with 
coordination of verbal storage and processing, and the duration of detection was negatively correlated with coordination of verbal storage and processing. Finally, regarding the detection of grammatical errors, the duration of the detection was negatively correlated with verbal storage and coordination of storage and processing, and the efficiency of detecting grammatical errors was positively correlated with verbal storage and coordination of storage and processing, as well as with strategic retrieval in long-term memory.

The regression analyses performed on the efficiency scores showed that five variables were significant predictors of the participants' performance during detection of errors: visuospatial storage; coordination of verbal storage and processing; strategic retrieval in longterm memory; effortful shifting; and level of errors processing, i.e., local (detections requiring the processing of a single word) versus global (detections requiring the processing of several words in a sentence). The level of errors processing showed a significant interaction with visuospatial storage, on the one hand, and with strategic retrieval in longterm memory, on the other; The significance of the prediction of detection efficiency by visuospatial storage and strategic retrieval in long-term memory, therefore, varies with the type of error.

Further analyses showed that visuospatial storage was a significant predictor of detection efficiency at a local level (typographical and lexical errors at the word level) but not when error detection required more global processing (grammar errors involving several words). In more details two variables significantly predict typographic error detection: visuospatial storage and coordination of verbal storage and processing. These same two variables were also significant predictors of the detection of lexical errors. It also should be noted that, although verbal storage and processing was positively related to efficiency in detection of typographical and lexical errors, i.e., that a high ability in coordination of verbal storage and processing predicted good detection efficiency, visuospatial storage was by 
contrast negatively related to detection of these two types of errors - namely, that high ability in visuospatial storage predicted a low detection performance. This last finding may come from the fact that high ability in visuospatial storage is also associated with a longer detection time but without quantitative improvement of detection, which resulted in a decrease in efficiency of detection.

Effortful shifting was also a predictor of detection of lexical errors. A low shifting ability (i.e., high effortful shifting) predicted better performance in lexical error. This is certainly because low switching ability would help individuals focus only on word level processing. By contrast, individuals with high shifting capacity would instead frequently alternate between local and global processing.

Finally, a single variable was a significant predictor of detection of grammatical errors: strategic retrieval from long-term memory. More precisely, strategic retrieval from long-term memory was a predictor of errors at a global level but not at a local error. This presumably comes from the fact that detecting such an error requires integrating different elements according to rules stored in long-term memory. Therefore, individuals' ability to retrieve knowledge from long-term memory is crucial to correctly analysing whether or not an error is present.

These findings confirm the decisive role of the level of processing involved for detecting an error (span of processing involving only one word versus multiple words) on error detection, already put forward by Larigauderie et al. (1998). The findings also confirm that different components of working memory are involved in the detection of errors, and that involvement of these components differs according to the nature of the error.

An interesting result from this point of view is that, for detection of the types of error types introduced in this study, the executive component of working memory related to the verbal domain appears to be more involved than the nonexecutive component of verbal 
storage, whereas the nonexecutive component of working memory related the visuospatial domain seems more determinative than the visuospatial executive component.

Finally, it is worth pointing out that the linguistic skills that enabled participants to apply the appropriate correction to an error did not predict the detection of typographical errors but added a significant amount of explained variance to that provided by working memory capacity in the case of lexical errors and grammatical errors. In sum, further research is needed to study the implications of executive and nonexecutive components of working memory in detection when simultaneously detecting different types of errors, and not, as is the case in this study, a single type of error. 


\section{References}

Adams, A.-M., Simmons, F., Willis, C., \& Pawling, R. (2010). Undergraduate students' ability to revise text effectively: relationships with topic knowledge and working memory. Journal of Research in Reading, 33 (1), 54-76.

Ardila, A. (2003). Language representation and working memory with bilinguals. Journal of Communication Disorders, 36, 233-240.

Baddeley, A. D. (1966). Short-term memory for word sequences as a function of acoustic, semantic, and formal similarity. Quarterly Journal of Experimental Psychology, 18, $312-365$.

Baddeley, A. D. (1986). Working memory. Oxford: University Press.

Baddeley, A. D. (1996). Exploring the central executive. The quarterly Journal of Experimental Psychology, 49A, 5-28.

Baddeley, A. D. (2000). The episodic buffer: A new component of working memory? Trends in Cognitive Science, 4, 417-423.

Beal, C., Bonitatibus, G. J., \& Garrod, A. C. (1990). Fostering children's revision skills through training in comprehension monitoring. Journal of Educational Psychology, $82,275-280$.

Brickenkamp, R. (1998). d2 test d'attention concentrée. Manuel [d2 test of focused attention. Manual]. Paris: ECPA.

Brickenkamp, R., \& Karl, G. A. (1986). Geräte zur messung von aufmerksamkeit, konzentration und vigilanz. In R. Brickenkamp (Ed.), Handbuch apparativer verfahren in der psychologie. Göttingen: Hogrefe.

Brunyé, T. T., Mahoney, C. R., Rapp, D. N., Ditman, T., \& Taylor, H. A. (2012). Caffeine enhances real-world language processing: Evidence from a proofreading task. Journal of Experimental Psychology: Applied. 18, 95-108.

Chromik, M. (2002). Proofreading, Its Value, and Its Place in the Writing Center. Available online: http://eric.ed.gov/?id=ED476401 (last retrieved on August, 19 2017).

Daneman M., \& Carpenter P. A. (1980). Individual differences in working memory and reading. Journal of Verbal Learning and Verbal Behavior, 19, 450-466.

Dedeyan, A., Largy, P., \& Negro, I. (2006). Mémoire de travail et detection d'erreurs d'accord verbal: étude chez le novice et l'expert. [Working memory and detection of verbal agreement errors: A study of novices and experts]. Langages, 164, 57-70.

Dedeyan, A., Olive, T., \& Largy, P. (2006). Implication des composants de la mémoire de travail dans la détection des erreurs d'accord sujet-verbe: approche développementale [Involvement of the different components of working memory in detecting subject-verb agreement errors: A developmental approach]. Paper presented at the International Conference on Cognitive Approach of Written Language Learning, Rennes, France, October.

Evans, W. S., Caplan, D., Ostrowski, A., Michaud, J., Guarino, A., \& and Waters, G (2015). Working Memory and the Revision of Syntactic and Discourse Ambiguities. Canadian Journal of Experimental Psychology/Revue canadienne de psychologie expérimentale, 69, 136-55.

Faigley, L., and Witte, S. (1981). Analyzing Revision. College Composition and Communication, 32, 400-414.

Fournier-Vicente, S., Larigauderie, P., \& Gaonac'h, D. (2008). More dissociations or interactions within central executive functioning: A comprehensive latent-variable analysis. Acta Psychologica, 129, 32-48. 
Friedman, N. P., \& Miyake, A. (2004). The relations among inhibition and interference control functions: A latent-variable analysis. Journal of Experimental Psychology: General, 133, 101-135.

Gignac, G. E., Kovacs, K., \& Reynolds, M. R. (2018) Backward and forward serial recall across modalities: An individual differences perspective. Personality and Individual Differences, 121, 147-151.

Gorsuch, R. L. (1983). Factor analysis. Philadelphia: W.B. Saunders Compagny.

Hacker, D. J., Plumb, C., Butterfield, E. C., Quathamer, D. \& Heineken, E. (1994). Text revision: Detection and correction of errors. Journal of Educational Psychology, 86, $65-78$.

Hargis, M. B., Yue, C. L., Kerr, T., Ikeda, K., Murayama, K., \& Castel, A. D. (2017). Metacognition and proofreading: The roles of aging, motivation, and interest. Aging, Neuropsychology and Cognition, 24, 216-226.

Hayes, J. R., (1996). A new framework for understanding cognition and affect in writing. In C. M. Levy, \& S. Ransdell (Eds), The science of writing: theories, methods, individual differences and applications (pp. 1-28). Mahwah, NJ: Lawrence Erlbaum Associates.

Juffs, A. (2004). Representation, processing and working memory in a second language. Transactions of the Philological Society, 102, 199-225.

Jung, J. (2018). Effects of task complexity and working memory capacity on L2 reading comprehension. System, 74, 21-37.

Kane, M. J., Hambrick, D. Z., Tuholski, S. W., Wilhelm, O., Payne, T. W. \& Engle, R. W. (2004). The generality of working memory capacity: A latent-variable approach to verbal and visuospatial memory span and reasoning. Journal of Experimental Psychology: General, 133, 189-217.

Kaiser, H. F. (1960). The application of electronic computer to factor analysis. Educational and Psychological Measurement, 20, 141-151.

Kellogg, R. T., (1996). A model of working memory in writing. In C. M. Levy, \& S. Ransdell (Eds), The science of writing (pp. 57-71). Mahwah, NJ: Lawrence Erlbaum, Associates.

Kessels, R. P. C., van den Berg, E., Ruis, C., \& Brands, A. M. A. (2008). The Backward Span of the Corsi-Block-Tapping Task and Its Association With the WAIS-III Digit Span. Assessment, 15, 426-434.

Kline, R. B. (1998). Principles and practice of structural equation modeling. New York: Guilford Press.

Larigauderie, P., Gaonac'h, D., \& Lacroix, N. (1998). Working memory and error detection in texts: what are the roles of the central executive and the phonological loop? Applied Cognitive Psychology, 12, 505-527.

Leeser, M. J. (2007). Learner-based factors in L2 reading comprehension and processing grammatical form: Topic familiarity and working memory. Language Learning, 57, 229-270.

Levy, B. A. (1983). Proofreading familiar text: Constraints on visual processing. Memory \& Cognition, 11, 1-12.

Levy, B. A., \& Begin, J. (1984). Proofreading familiar text: Allocating resources to perceptual and conceptual processes, Memory \& Cognition, 12, 621-632.

Levy, B.A., Newell, S., Snyder, J., \& Timmins, K. (1986). Processing changes across reading encounters. Journal of Experimental Psychology: Learning, Memory and Cognition, $12,467-78$. 
Levy, B. A., Di Persio, R., \& Hollingshead, A. (1992). Fluent rereading: Repetition, automaticity, and discrepancy, Journal of Experimental Psychology: Learning, Memory, and Cognition, 18, 957-971.

Lezak, M. (1983). Neuropsychologica Assessrnent. New York: Oxford University Press.

McCutchen, D., Francis, M., \& Kerr, S. (1997). Revising for meaning: Effects of knowledge and strategy. Journal of Educational Psychology, 89, 667-676.

Miyake, A., \& Friedman, N. P. (1998). Individual Differences in Second Language Proficiency: Working Memory as Language Aptitude. In A. F. Healy, \& L. E. Bourne (Eds.), Foreign Language Learning: Psycholinguistic Studies on Training and Retention (pp. 339-364). Mahwah, NJ: Lawrence Erlbaum Associates.

Miyake, A., Friedman, N. P., Emerson, M. J., Witzki, A. H., Howerter, A., \& Wager, T. D. (2000). The unity and diversity of executive functions and their contributions to complex "frontal lobe" tasks: A latent variable analysis. Cognitive Psychology, 41, 49-100.

Piolat, A., \& Médard, S. (1998). Effects of the reading span and of the spelling level of writers for revising spelling problems. Meeting of the SIG Writing E.A.R.L.I. "Writing and Learning to Write at the Dawn of the $21^{\circ}$ Century, Poitiers, France, July 2-4.

Piolat, A., Roussey, J. Y., Olive, T., \& Arnada, M. (2004). Processing time and cognitive effect in revision: effects of error type and of working memory capacity. In L. Allal, L. Chanquoy \& P. Largy (Eds), Revision. Cognitive and instructional processes (pp. 21-38). Boston: Kluwer Academic Publishers.

Reitan, R. M., \& Wolfson, D. (1985). The Halstead-Reitan Neuropsycholgical Test Battery: Therapy and clinical interpretation. Tucson, AZ: Neuropsychological Press.

Reynolds, C. (1997). Forward and Backward Memory Span should not be combined for clinical analysis. Archives of Clinical Neuropsychology, 12, 29-40.

Roussey, J.-Y., \& Piolat, A. (2008). Critical reading effort during text revision. European Journal of Cognitive Psychology, 20, 765-792.

Salthouse, T. A. (2011). What cognitive abilities are involved in trail-making performance? Intelligence, 39, 222-232.

Shafto, M. A. (2015). Proofreading in Young and Older Adults: The Effect of Error Category and Comprehension Difficulty, International Journal of Environmental Research and Public Health, 12, 14445-14460.

Spector, A., \& Biederman, I. (1976). Mental set and mental shift revisited. American Journal of Psychology, 89, 669-679.

Spreen, O., \& Strauss, E. (1998). A Compendium of Neuropsychological Tests: Administration, Norms, and Commentary. New-York: Oxford University Press.

Stroop, J. R. (1935). Studies of interference in serial verbal reactions. Journal of Experimental Psychology, 18, 643-662.

Tabachnick, B. G., \& Fidell, L. S. (2001). Using multivariate statistics (4 ${ }^{\text {th }}$ ed.). Northridge: Harper Collins.

Towse, J. N., \& Neil, D. (1998). Analyzing human random generation behavior: A review of methods used and a computer program for describing performance. Behavior Research Methods, Instruments, \& Computers, 30, 583-591.

Walter, C. (2004). Transfer of reading comprehension skills to L2 is linked to mental representations of text and to L2 working memory. Applied Linguistics, 25, 315-339.

Waters, G. S., \& Caplan, D. (1996). The measurement of verbal working memory capacity and its relation to reading comprehension. The Quarterly Journal of Experimental Psychology, 49(A), 51-79.

Zabrucky, K., Moore, D., \& Schultz, N. R. (1993). Young and old adults' ability to use different standards to evaluate understanding. Journal of Gerontology, 48, 238-244. 


\section{Appendix 1}

Regression analyses predicting efficiency in error detection (number of errors detected per minute) from executive and nonexecutive working memory measures, level of errors (local vs global) and interactions between level of errors and the different nonexecutive and executive functions

\begin{tabular}{|c|c|c|c|c|}
\hline Variables & $\mathrm{B}$ & $t(73)$ & $F(1,73)$ & $p$ \\
\hline \multicolumn{5}{|c|}{ Model 1A } \\
\hline Verbal storage & -0.01 & -.08 & 0.01 & .94 \\
\hline Visuospatial storage & -0.19 & -2.07 & 4.30 & .04 \\
\hline$V$-Coord & 0.71 & 2.55 & 6.52 & .01 \\
\hline VSP-Coord & 0.15 & 0.55 & 0.30 & .58 \\
\hline$S R-L T M$ & 0.51 & 2.49 & 6.18 & .015 \\
\hline SHIFT-E & 0.42 & 2.06 & 4.26 & .04 \\
\hline Error processing level & -0.55 & $t(78)=-5.30$ & $F(1,78)=28.12$ & $<.0001$ \\
\hline $\begin{array}{l}\text { Error processing level } * \\
\text { Verbal storage }\end{array}$ & 0.05 & $t(78)=1.30$ & $F(1,78)=1.68$ & .20 \\
\hline \multicolumn{5}{|c|}{ Model 1B } \\
\hline Verbal storage & -0.01 & -0.08 & 0.01 & .94 \\
\hline Visuospatial storage & -0.19 & -2.07 & 4.30 & .04 \\
\hline$V$-Coord & 0.71 & 2.55 & 6.52 & .01 \\
\hline VSP-Coord & 0.15 & 0.55 & 0.30 & .58 \\
\hline$S R-L T M$ & 0.51 & 2.49 & 6.18 & .015 \\
\hline SHIFT-E & 0.42 & 2.06 & 4.26 & .04 \\
\hline Error processing level & -0.55 & $t(78)=-5.40$ & $F(1,78)=29.13$ & $<.0001$ \\
\hline $\begin{array}{l}\text { Error processing level } * \\
\text { Visuospatial storage }\end{array}$ & 0.07 & $t(78)=2.13$ & $F(1,78)=4.53$ & .04 \\
\hline \multicolumn{5}{|c|}{ Model 1C } \\
\hline Verbal storage & -0.01 & -0.08 & 0.01 & .94 \\
\hline Visuospatial storage & -0.19 & -2.07 & 4.30 & .04 \\
\hline$V$-Coord & 0.71 & 2.55 & 6.52 & .01 \\
\hline VSP-Coord & 0.15 & 0.55 & 0.30 & .58 \\
\hline$S R-L T M$ & 0.51 & 2.49 & 6.18 & .015 \\
\hline SHIFT-E & 0.42 & 2.06 & 4.26 & .04 \\
\hline Error processing level & -0.55 & $t(78)=-5.25$ & $F(1,78)=27.57$ & $<.0001$ \\
\hline Error processing level $*$ & -0.04 & $t(78)=-0.34$ & $F(1,78)=0.11$ & .74 \\
\hline V-Coord & & & & \\
\hline \multicolumn{5}{|c|}{ Model 1D } \\
\hline Verbal storage & -0.01 & -0.08 & 0.01 & .94 \\
\hline Visuospatial storage & -0.19 & -2.07 & 4.30 & .04 \\
\hline V-Coord & 0.71 & 2.55 & 6.52 & .01 \\
\hline VSP-Coord & 0.15 & 0.55 & 0.30 & .58 \\
\hline$S R-L T M$ & 0.51 & 2.49 & 6.18 & .015 \\
\hline SHIFT-E & 0.42 & 2.06 & 4.26 & .04 \\
\hline Error processing level & -0.55 & $t(78)=-5.25$ & $F(1,78)=27.54$ & $<.0001$ \\
\hline $\begin{array}{l}\text { Error processing level } * \\
\text { VSP-Coord }\end{array}$ & 0.01 & $t(78)=0,14$ & $F(1,78)=0.02$ & .89 \\
\hline
\end{tabular}


Model 1E

\begin{tabular}{lllll} 
Verbal storage & -0.01 & -0.08 & 0.01 & .94 \\
Visuospatial storage & -0.19 & -2.07 & 4.30 & .04 \\
V-Coord & 0.71 & 2.55 & 6.52 & .01 \\
VSP-Coord & 0.15 & 0.55 & 0.30 & .58 \\
SR-LTM & 0.51 & 2.49 & 6.18 & .015 \\
SHIFT-E & 0.42 & 2.06 & 4.26 & .04 \\
Error processing level & -0.55 & $t(78)=-5.39$ & $F(1,78)=29.10$ & $<.0001$ \\
Error processing level $*$ & 0.22 & $t(78)=2.11$ & $F(1,78)=4,45$ & .04 \\
SR-LTM & & & & \\
\hline & & Model 1F & & \\
Verbal storage & -0.01 & -0.08 & 0.01 & .94 \\
Visuospatial storage & -0.19 & -2.07 & 4.30 & .04 \\
V-Coord & 0.71 & 2.55 & 6.52 & .01 \\
VSP-Coord & 0.15 & 0.55 & 0.30 & .015 \\
SR-LTM & 0.51 & 2.49 & 6.18 & .04 \\
SHIFT-E & 0.42 & 2.06 & 4.26 & .0001 \\
Error processing level & -0.55 & $t(78)=-5.26$ & $F(1,78)=27.67$ & .52 \\
Error processing level * & -0.07 & $t(78)=-0.64$ & $F(1,78)=0.41$ & .52 \\
SHIFT-E & & & & \\
\hline
\end{tabular}

Note. V-Coord: Coordination of verbal storage and processing (factorial scores on Factor 4 PCA); VSP-Coord: Coordination of visuospatial storage and processing (factorial scores on Factor 1 PCA); SR-LTM: Strategic retrieval in long-term memory (factorial scores on factor 2 PCA); SHIFT-E: Effortful Shifting (factorial scores on Factor 3 PCA); Error processing level: Local (detections requiring the processing of a single word, i.e., typographical and lexical errors) versus Global (detections requiring the processing of several words in a sentence, i.e., grammatical errors) processing level 